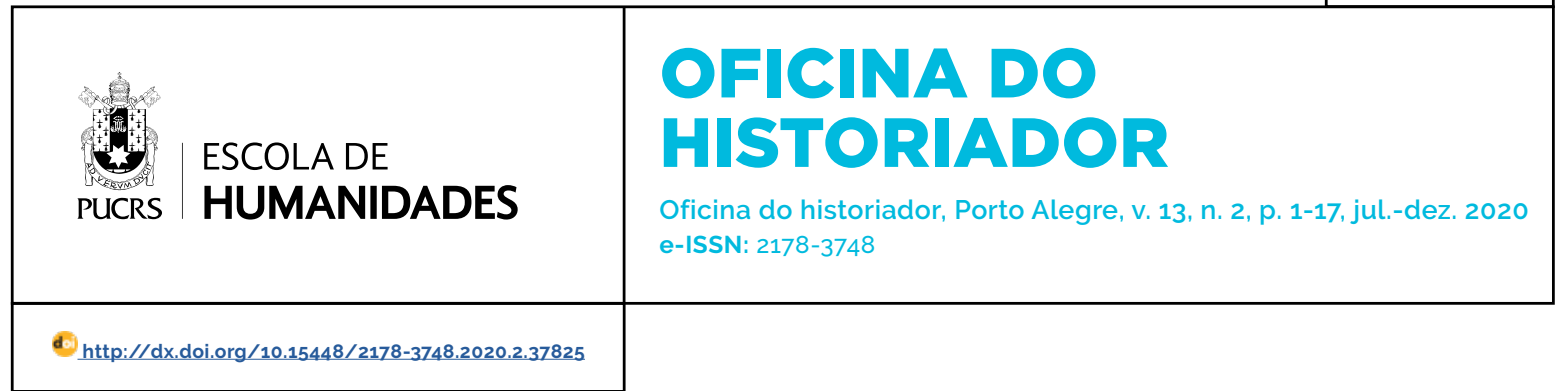

SEÇÃO: DOSSIÊ

\title{
Aportes da História Ambiental à História Agrária da Bacia do Prata, primeira metade do século XIX. Uma proposta pedagógico-didática ${ }^{1}$
}

\author{
Contributions of Environmental History to the Agrarian History of the Cuenca del Plata, \\ first half of the 19th century. A pedagogical-didactic proposal
}

\author{
Silvia Lilian Ferro² \\ orcid.org/0000-0003-2551-801X \\ Lilian.ferro@unila.edu.br
}

Recibido en: 26/04/2020. Acceptado en: 13/06/2020.

\begin{abstract}
Resumo: Esta comunicação propõe-se, em primeiro lugar, uma revisão de acordo com as contribuições da História Ambiental, para a interpretação clássica dos processos históricos da primeira metade do século XIX na Bacia do Prata, com ênfase nos sistemas sócio agrários e suas relações com o surgimento de formas de organização política que dariam lugar ao processo laborioso e conflitivo de formação dos Estados Nacionais, que se estendeu por grande parte daquele século. As possibilidades e os desafios de acrescentar ao meio ambiente como sujeito histórico, são analisados em um espaço e temporalidade concretos, baseados na centralidade de uma forma típica de produção agrária que é a estância platina, que por muito tempo têm moldado as relações políticas, sociais e culturais das sociedades da região e continuam se projetando no presente. amplamente ressignificadas, compondo identidades territoriais transnacionais. Em segundo lugar, propõe-se uma contextualização institucional e pedagógica de tais desafios, com base na experiência no ensino da Disciplina de História Rural e Agrária da América Latina no Programa de Pós-graduação em Ensino da História e da América Latina da Universidade Federal da Integração Latino-americana (UNILA), Brasil. Por meio de revisão bibliográfica e análise de discurso de fontes primárias, verifica-se que a "ambientalização" desses subcampos epistemológicos ainda é uma possibilidade a ser desenvolvida, com relação aos temas e período aqui considerados, mas com grande potencial para renovar e autonomizar as premissas teórico-metodológicas das disciplinas envolvidas.
\end{abstract}

Palavras-chave: História Agrária. Bacia do Prata. Estâncias. Estados Nacionais. História Ambiental.

Abstract: This communication proposes firstly, a revisit- in line with the contributions of Environmental History- to the classic interpretation of historical processes of the first half of the 19th century in the River Plate Basin, with emphasis on socio-agrarian systems and their relationship with the emergence of forms of political organization that would give way to the laborious and conflictive process of formation of National States, spanning much of that century. Possibilities and challenges of adding to the environment as a historical subject are analyzed, in a concrete space and temporality based on the centrality of a typical form of agrarian production that is the River Plate's ranche, which for a long time shaped the social, political and cultural relations of the societies in the region and continue projecting themselves in the present, largely resignified, composing transnational territorial identities. Secondly, an institutional and pedagogical contextualization of such challenges is proposed based on the experience in teaching Latin American Rural and Agrarian History in the Postgraduate Program in "Ensino da História e da América Latina" of the Universidade Federal da Integração Latino-americana (UNILA), Brazil. Through the bibliographic review, it is verified that the "greening" of these epistemological area is still a possibility to be developed, regarding the topics and period considered here, but with great potential to renew and auto- 
nomize the theoretical-methodological assumptions of the mentioned disciplines.

Key words: Agrarian History. River Plate Basin. Ranches. National states. Environmental History.

\section{Introducción}

Este articulo, se propone una revisita a la interpretación clásica de procesos históricos de la primera mitad del siglo XIX en la Cuenca del Plata, analizando las posibilidades de incluir al ambiente como sujeto histórico en el entendimiento del pasado, así como sus limitaciones y desafios metodológicos. En las últimas décadas, tanto en la construcción del conocimiento científico como en las politicas públicas y en el debate colectivo se advierte que el ambiente va dejando de ser visto apenas como un escenario inerte y afectado unidireccionalmente por las transformaciones antrópicas (Leff, 2003) para ser considerado cada vez más, como una fuerza histórica de protagonismo equivalente al de la especie humana; la cual hace parte del mismo y no al contrario. Se interroga también sobre la pertinencia de categorias y conceptos que nos permitan comprender la compleja relación entre ambiente, región histórica, formas de producción agraria y su incidencia en las caracteristicas de los conflictos en la primera mitad del Siglo XIX en la región. Periodo atravesado por crónicas inestabilidades debido a demarcaciones y redefiniciones de fronteras en el surgimiento embrionario de los Estados Nacionales actuales que coexisten en ese territorio.

Esta opción reconoce influencias de circunstancias de diversa índole. Por una parte, en los últimos años asistimos a una "ambientalización" de las Ciencias Sociales y de las Humanidades. Las perspectivas ambientales convocan a una deconstrucción del conocimiento de lo "humano" y lo "natural", presentada en forma binaria desde la Modernidad', que se proponen como categorias no solo separadas y diferenciadas sino también jerárquicas. En tal contexto la Historia Ambiental surge en las últimas décadas como una posibilidad rupturista, superando la autorreferencialidad de lo humano en la connotación de lo "histórico", incorporando al ambiente como un sujeto histórico que contiene a lo humano condicionándolo y a su vez es transformado por éste. Una suerte de actualización de la propuesta braudeliana de principios del Siglo XX.

\begin{abstract}
O ambiente irrompeu no discurso político e científico de nosso tempo como um conceito que vem ressignificar as concepções de mundo, de desenvolvimento, da relação da sociedade com a natureza, de tempo e da sustentabilidade da vida. O ambiente emerge como um pensamento holístico que busca reintegrar as partes de uma realidade complexa; é o campo de saber que viria completar as visões parciais e o desconhecimento da natureza por parte dos paradigmas científicos da modernidade. Desta maneira, uma série de disciplinas científicas, de práticas profissionais e de ações sociais vem se "ambientalizando". Dentre elas, uma das mais atrasadas entre as ciências sociais é a história. (Leff, 2003, p. 11)
\end{abstract}

Por otra parte, la consideración de las características institucionales de la UNILA donde se imparte la Disciplina História Rural y Agrária Latino-americana, evidencia que las mismas forman parte también de un "ambiente" que debe ser considerado, tanto en la propuesta curricular como en la pedagógica y didáctica para la práctica docente, orientada por el enfoque histórico-crítico (Saviani, 2008) y para la profundización epistemológica y metodológica en la investigación.

La incorporación de indígenas aldeados en forma significativa al sistema público de educación superior brasileño, por ende, a la UNILA, es parte de una política pública creada en los últimos años, buscando incrementar su participación en este nivel educativo. Esta circunstancia, ofreció un estímulo para discutir las posibilidades de renovación que la Historia Ambiental ofrece a la Historia Rural y Agraria, debido a que la presencia de integrantes de estos grupos étnicos, creciente en términos cuantitativos a partir de estas politicas, deseablemente fomentaría diálogos e interacciones en la forma de conocer, comprender y transmitir a las generaciones del presente el pasado de nuestras sociedades.

Se espera además que esta presencia más

2 -Aunque las matrices epistemológicas de la dualidad humanidad-Naturaleza pueden rastrearse hasta la Filosofía clásica greco-romana. 
expresiva en la Universidad contribuya a una interrogación sobre supuestos "naturalizados" en la forma de construir conocimiento histórico: ¿existiría acaso desde el punto de vista de pueblos originarios la posibilidad de excluir al ambiente como parte de la explicación de los procesos históricos? El dualismo naturaleza- cultura tendría algún sentido si se quiere dialogar con otras formas de entender la historia común, aunque diversa, de nuestras sociedades latino-americanas? Si no hay interrogación y resignificación sobre el propio hacer en una situación de convivencia intercultural como la mencionada, la idea de inclusión educativa de minorias étnicas quedaria reducida a la idea de presencia, tal como se ha tratado al ambiente hasta recientemente, considerados, ambos, un mero telón de fondo para el continuo despliegue de racionalidades ensimismadas y jerárquicas.

Finalmente, la propia misión institucional de UNILA estimula-por espontáneo hacer y convivencia-el uso de categorias y perspectivas que sobrepasen las barreras nacionales identitarias que se establecen dentro de las fronteras estatales, tanto en la práctica docente como en la extensión y en la investigación. Universidad bilingüe en lo formal pero multilingüe en la realidad, marcada por la presencia mayoritaria de alumnos brasileros rondando el $70 \%$ y al menos otras 24 nacionalidades, constituyendo aproximadamente el $30 \%$ por ciento de alumnos no brasileros tanto de graduación como de posgraduación. En un espacio educativo tan diverso desde cualquier categoria o indicador que se quiera tomar (pluri-étnico, plurinacional, pluriconfesional y plurilingüístico) las demarcaciones nacionales en el lugar del habla, se vuelven un obstáculo porque tensionan las prácticas y legitimaciones plurales y equipotentes de saberes.

Análogamente, el cuerpo docente también se aproxima a la proporción 70/30 entre profesores brasileros y no brasileros, lo cual propiciaria salir de cánones domésticos de referencias autorales, de temáticas y de corrientes epistemológicas que usualmente gravitan en la gran mayoría de universidades nacionales o federales de la región de composición cultural, étnica, nacional y lingüística menos heterogénea. Suele ocurrir en estas instituciones, en la práctica de la docencia y en la investigación histórica, que repertorios de enfoques, marcos teóricos y autorias consagradas adquieren la rigidez propia que demuestran muchas veces quienes aspiran al reconocimiento y legitimación por parte de sus pares, adscribiéndose en gran medida a lo que se "debe" conocer y saber hacer.

Sin embargo, aun en una universidad tan intercultural como ésta, se nota claramente, cuáles son los limites tanto formales como substantivos, de la integración inter e intra-nacional en curriculos y en proyectos pedagógicos de las carreras. Tener matriculas conformadas por alumnos de diferentes nacionalidades y etnias, asi como entre docentes, pero al mismo tiempo imponer agendas de temas y bibliografias del canon científico y disciplinar hegemónico de un solo país contraria per se el esfuerzo integracionista el cual, para existir efectivamente, precisa de la escala regional y transnacional en cada mirada disciplinar. Un enfoque "latino-americanista" con todas las controversias que tal concepto encierra, y que escapa al foco de este artículo, no es apenas analizar cuestiones de otros paises o regiones transnacionales conservando una mirada localista, sino que precisa regionalizar las epistemologias, metodologías e historiografías en este caso. Por todo ello, pensarse en sentido ambiental facilita una identidad "integracionista"3 mucho más clara, fuerte y constante temporalmente, que bloques comerciales acuerdos y tratados que mudan según coyunturas ideológico-gubernamentales.

Desde las vivencias en la Triple Frontera entre Argentina, Brasil y Paraguay donde la Universidad está situada4, se evidencia que es precisamente la región histórica común quien otorga

\footnotetext{
3 -Por ejemplo, en la actualidad la cuenca amazónica es compartida por ocho países sudamericanos, otro caso es el Gran Chaco americano, identificado como región ecológica desde etapas precolombinas y es compartido actualmente por cuatro países, asi como la Cuenca del Río de la Plata es compartida por cinco paises, repitiéndose algunos paises en su participación territorial en los diferentes ecosistemas transnacionales mencionados. Lo que impone y exige esfuerzos de gestión compartida y colaborativa transnacional.

4 -Está situada en la ciudad brasilera de Foz de Iguaçu, creada en 2010 mediante Lei $n^{\circ} 12.189$.
} 
significados compartidos a prácticas culturales, como es evidente en el ejemplo de la práctica de beber mate que brasileños del sur, argentinos y paraguayos siguen adoptando masivamente a pesar de las particiones, jurisdiccionalidades y denominaciones que sufrió ese territorio en más de cinco siglos y hasta lo hacen uruguayos ${ }^{5}$ como únicos conversos del hábito del mate, por fuera de la región histórico-ambiental de la yerba mate. Es decir, el ambiente posibilitó prácticas culturales que subsisten, independientemente de la nacionalidad y la lengua que se posean al hacer parte de ellas, cuando se está en la región histórica que las sustenta.

\section{El ambiente como problema y como sujeto histórico}

En el último tercio del siglo XX, las perspectivas ecologistas en diálogo con las Humanidades, Ciencias Sociales y hasta políticas públicas no lograron quebrar, debido a sus propias limitaciones epistemológicas, la autorreferencialidad mencionada antes aquí. Aun en la ecología histórica, el antropocentrismo continúa intocado porque en esa perspectiva el acontecer humano en su temporalidad irreversible, afectaria unidireccionalmente al ambiente debido a la transformación continua del mismo para satisfacer sus necesidades y deseos, especialmente por medio de la agricultura y otras actividades consideradas "extractivas" por su alto nivel predatorio. El ambiente en esta perspectiva continúa en rol pasivo y postrado.

En tal contexto, la Historia Ambiental surge en las últimas décadas como una posibilidad rupturista, incorporando al ambiente como un sujeto-actor histórico que contiene a lo humano y también lo condiciona en múltiples formas, no apenas como un mero telón de fondo opaco o invisible en la explicación e interpretación de la temporalidad de la experiencia humana. Recupera, en definitiva, la propuesta braudeliana ${ }^{6}$ de principios del Siglo XX para la Historia-Disciplina, actualizándola: "cabría señalar que ella se ocupa de las interacciones entre las sociedades humanas y el mundo natural, y de las consecuencias de esas interacciones para ambas partes a lo largo del tiempo" (Castro Herrera, 2004:99). La Historia Ambiental, no es la historia del ambiente ni plantea una agenda temática nueva. Su desafio mayor consiste en revisar y resignificar el conocimiento histórico ya construido, para asi poder dar cuenta de las posibilidades reinterpretativas de los procesos históricos, esta vez con el ambiente incluido e interactuando.

\begin{abstract}
O ambiente não poderá, então, ser confundido com "a ecologia", sem o perigo de reduzir a história ambiental a uma história natural. Em contrapartida, a história ambiental também não poderia seguir o sentido de um determinismo econômico, no qual as relações sociais de produção ou a luta de classes seguem operando as transformações da vida material e espiritual dos povos e nações, ignorando as condições impostas pela natureza e pela cultura à organização e à mudança social.[...]. A história ambiental será o encontro de racionalidades diferenciadas para cuja abordagem, a definição genérica de ambiente como o campo das relações sociedade-natureza, abre a porta dos estudos de suas complexas interações. (Leff, 2003, p. 12).
\end{abstract}

La propuesta de la Historia Ambiental como estructural renovación para todas las áreas de conocimiento tradicionales de la Historia, llega con fuerza a los espacios académicos latino-americanos, muy especialmente a Brasil, notándose ello en la creación de espacios académicos y en la creciente producción de literatura científica. En realidad Latino-américa y especialmente Brasil ya protagonizaran este espacio epistemológico desde sus inicios, pero adscripto en gran medida a ser objetos de tales conocimientos. Quizás la novedad ahora es la decisión de ser también productores de esos conocimientos. Podría pensarse que la Historia Agraria y la Historia Rural especialmente serian, por sus especificidades temáticas dentro de los campos epistemológicos especíicos de la Historia-Ciencia tradicional, los espacios sub-disciplinares más proclives a introducir y sintetizar los aportes transformadores

\footnotetext{
5 - La población de la República Oriental del Uruguay es la mayor consumidora per cápita de yerba mate por habitante, aunque toda la yerba alli consumida es producida en el sur de Brasil al estilo "canaria" demandada por sus destinatarios.

6 -Otro de los precursores desde esta perspectiva, Emmanuel Le Roy Ladourie, miembro de la Escuela de Annales, incluye al ambiente como actor histórico especialmente en su_Histoire des paysans français de la peste noire à la Révolution (2006 en versión en francés y 2007 en versión traducida al portugués).
} 
de la Historia Ambiental porque sus objetos: la producción agraria y el espacio rural; estarian en directa interacción con lo que de forma tradicional, binaria y reduccionista llamariamos "naturaleza", connotando todo aquello fuera de lo humano y también fuera de la ciudad.

Son los espacios físicos y sus particularidades geológicas, edafológicas, hidrológicas, climáticas, pluviales- y claro está la historicidad inherente a cada uno de esos aspectos-que denominamos ecosistemas, los que posibilitan cada tipo de producción y que influencian desde sus particularidades, las formas de organización de la producción agraria y no agraria, así como a las relaciones sociales entrelazadas en ella. En particular es el sistema cultural quien expresa simbólicamente dichas particularidades, traduciéndolas como identidades territoriales por encima de fronteras politicas. ¿Pero seria posible introducir un enfoque holístico como este a la investigación de agendas temáticas de Historias Agrarias construidas desde sus tradiciones, debates y autorias de referencia con recortes meramente nacionales como viene ocurriendo? Al respecto Silva y Linhares (1995) nos responden: "Por suas próprias características, e bem ao contrário da história econômica tradicional, a história agrária não poderia ser uma história "nacional" (p.17).

El ambiente como recorte espacial y temporal ecosistémico, ofrece una real posibilidad para "desalambrar", porque los procesos históricos que lo constituyen anteceden y superan la compartimentalización de las fronteras establecidas por los estados nacionales. Esa unidad de sentido territorial y cultural que es la Cuenca del Plata, preexistente y subsiste por encima de demarcaciones administrativas. Esto fue percibido tempranamente también por los europeos ya en la etapa de la Conquista y Colonización sudamericana. Félix de Azara titula sus "Memorias sobre el estado rural del Rio de la Plata en 1801; demarcación de límites entre el Brasil y el Paraguay a últimos del siglo XVIII, é informes sobre varios particulares de la América Meridional española" anteponiendo la marca ambiental regional y abarcadora de recortes "nacionales" heredados de intereses imperiales ibéricos en el área.

Por todo ello, un concepto de utilidad para incluir la perspectiva ambiental en la historia agraria rioplatense, recuperado de las discusiones entre geógrafos e historiadores en las décadas de los 60 y 70 del siglo XX en Brasil, es el de região histórica (da Silva e Linhares, 1995). Región histórica aqui en un sentido de territorialidad ampliada, epistemológica, que trascienda las fronteras teóricas que imponen las agendas nacionales y le otorgue especificidad, a diferencia de la vaguissima noção de espaço (p.19) impulsada por la geografía brasileña de inspiración marxista7 que a su vez se mostró inviable en una posible práctica "local" para otros autores: "O modelo básico de análise proposto pela historiografía francesa-buscar na geografía os quadros de la historia agrária- afigurava-se para nós como uma realização impossivel." (p.20). Sin embargo, la influencia de geógrafos en la constitución del campo de la Historia Agraria brasilera y de allí también rioplatense, colocó en primer plano algunas cuestiones válidas desde la perspectiva ambiental, como las categorias espacio y región histórica. Se percibe también que la reflexión sobre el espacio se "tercerizó" a la Geografía y afines y la Historia-Ciencia habria abandonado la preocupación epistemológica por el espacio.

Para existir como tal y para impulsar una renovación en otros campos subdisciplinares la Historia Ambiental precisa colocar en la reflexión histórica al espacio como materialidad diacrónica y sincrónica que hace posible el devenir humano. No necesariamente la idea de territorio incluye todas las posibilidades de especificar un espacio dado y reconocer en él, como sucede habitualmente en los abordajes sobre el espacio de las "Historias Ambientales" domésticas. El espacio atravesado por la irreversibilidad creadora y transformadora del tiempo (Prigogine, 1994) que antecede y envuelve también a lo humano, es una condición esencial para que exista un ambiente y de alli un territorio. Aunque ya fue claramente advertido en

7 -Es la obra del geógrafo marxista brasilero Milton Santos a la que aluden los geógrafos en la cita. 
la etapa de Annales en las primeras décadas del siglo XX, existe un peligro inherente al incorporar al ambiente como sujeto histórico equiparable con la acción humana en la narración histórica de deslizarse hacia reduccionismos o simplificaciones. Es decir, la posibilidad de oscilar entre el determinismo ambiental y el posibilismo humano o autorreferencial ya fue confrontado por Braudel colocando esas posibilidades en diferentes temporalidades, pero interactuando éstas entre sí: "Para Fernand Braudel los tiempos largos de la naturaleza o "capas de historia lenta" se entrelazan con las duraciones, algunas completamente breves, de la historia de los eventos humanos. La naturaleza pasaba a ser, entonces, un agente activo de la historia." (Rubio Durán, 2011:106).

\subsection{Apuntes metodológicos}

Precisamente en el espacio denominado América Latina, la Historia Agraria es en si misma una Historia Total, debido a la gravitación que sus objetos de estudios "clásicos" tienen en la comprensión de la formación de sus estructuras de poder, tanto en el periodo colonial como pós-independencias. Especialmente hasta el siglo XIX, podriamos decir que hasta la Historia Política es en definitiva una explicación de la "agrarización" del poder político y de la desigualdad social resultante.

Por ello, la cuestión de la metodología plantea desafios no menores para la inclusión de una perspectiva ambiental en tópicos y escalas geográficas de formas de producción agraria de etapas pretéritas. Necesariamente, una perspectiva ambiental trae la exigencia de un enfoque regional y transnacional no solo en lo que respecta al recorte espacial del análisis, sino que eso incluye a autorias y agendas temáticas de los casos nacionales que integran una región histórica en particular. Hasta el momento las miradas a lo regional se hacen desde lo local, o por parte de equipos interdisciplinarios e internacionales que se organizan para analizar un aspecto puntual en un territorio dado cada uno desde su tradición epistemológica y metodológica. Desde esta propuesta se considera que sería deseable que tales equipos se formen para construir interpretaciones históricas regionales y transnacionales nuevas, originales y de sintesis. No solo meras colecciones "amosaicadas", collage de miradas particulares sobre un tema común, como parece funcionar lo que ahora denominamos "enfoques regionales" en la historiografia agraria y rural latino-americana.

Por otra parte, la consulta de archivos y fuentes en la investigación de temas y enfoques de Historia Agraria Latinoamericana tradicional, aun en la etapa de subordinación de la misma a la Historia Económica, sigue siendo una práctica metodológica fundamental y necesaria en la revisita al periodo y a las prácticas agrarias analizadas. Lo que cambia es que la interrogación sobre esas fuentes, acerca de la presencia o ausencia del ambiente en ellas, puede mejorar nuestra comprensión de tales procesos.

La Historia Ambiental, como posibilidad renovadora para la Historia Agraria, debería propiciar prácticas que puedan ser innovadoras en sentido epistemológico, colocando el ambiente como actor histórico en diálogo con las formas de organización de la producción agraria y sus relaciones sociales, pero conservadora en sus prácticas metodológicas. Intensificando el trabajo documental en sentido extenso, revisitando análisis de fuentes primarias de todo tipo procurando establecer cómo los actores "humanos" de la etapa, perciben y se relacionan con condicionamientos y posibilidades que coloca el ambiente, en su hacer cotidiano de procura y cultivo de alimentos para consumo y para comercialización.

Una perspectiva teórica amplia, incorporando el ambiente como actor histórico, permite transitar archivos ya utilizados en investigaciones de tipo "tradicional", procurando referencias de los actores, es decir sus percepciones directas e indirectas, sobre condicionamientos, impactos y fortalezas del ambiente en la organización de los sistemas productivos que los sustentaron y gracias a los cuales crearon circuitos de comercialización que afianzaron sistemas sociales, también éstos fuertemente influenciados por tales características. 


\section{Ambiente y producción agraria en la} Cuenca platina

Por Cuenca del Plata, la Méditerranée de los sudamericanos del sur, nos referimos al espacio hidrico-territorial con un área aproximada de $3.170 .000 \mathrm{~km}^{2}$ la segunda mayor de Sudamérica después de la Cuenca Amazónica y quinta en el mundo por superficie ${ }^{8}$ y cantidad de cursos de agua "Las aguas de dos grandes ríos confluyen en el Río de la Plata: el Paraná y el Uruguay que, a su vez, recogen el caudal de otros ríos muy importantes, como el Paraguay, el Bermejo, el Pilcomayo y el Iguazú, entre muchos otros ${ }^{9}$.

Ilustración - Cuenca del Plata.

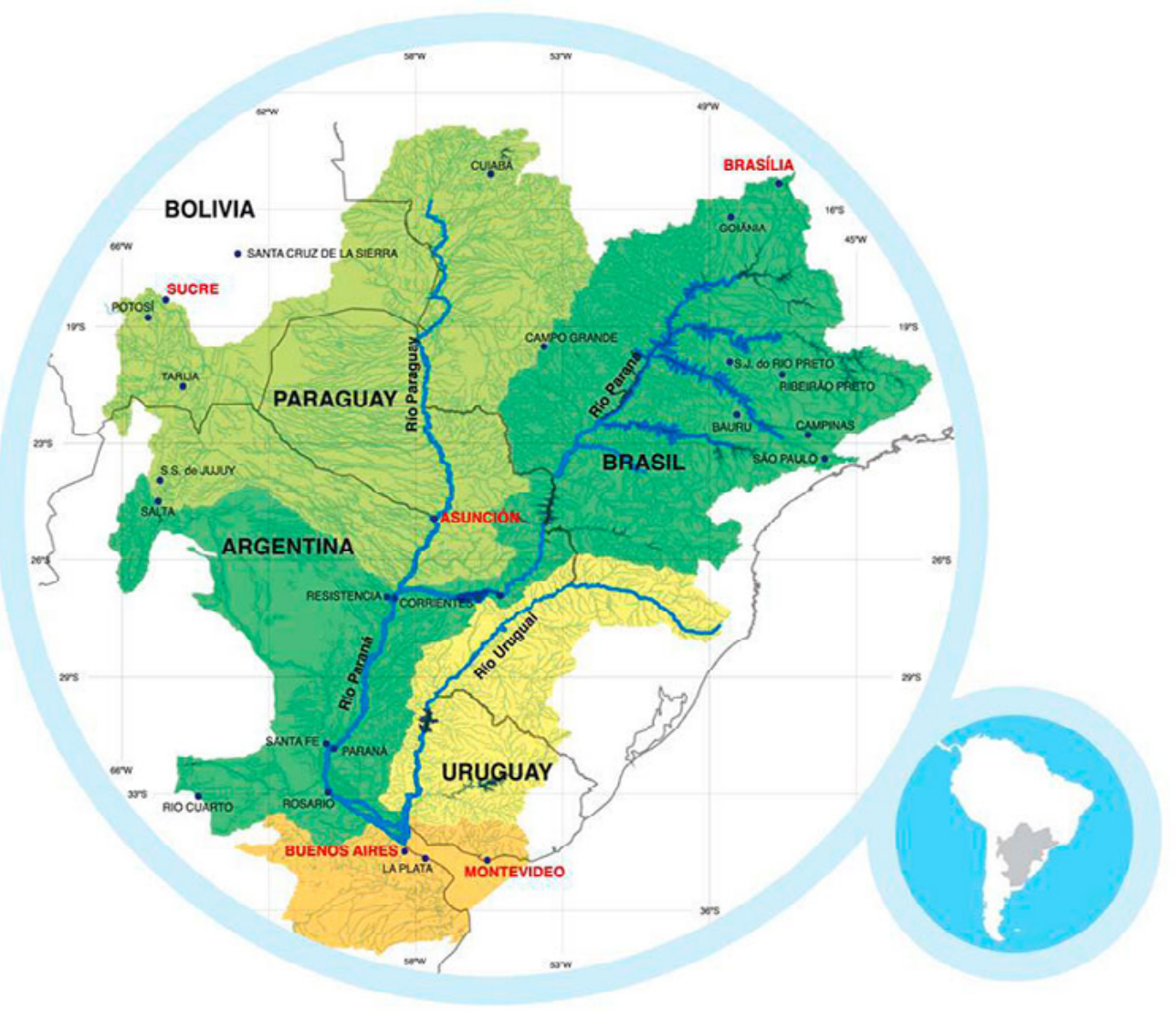

Fuente: Comisión mixta del Río Paraná. (COMIP)10

Las transformaciones ambientales más profundas y aceleradas acontecieron en la etapa de la Conquista y Colonización ibérica de la Cuenca, siendo ellas características de los procesos históricos que el historiador ambiental Alfred Crosby (2011) denominó a escala global "imperialismo ecológico", dado que elementos de la fauna y la flora fueron trasladados desde ecosistemas europeos y de sus dominios en Asia y África; hacia los territorios americanos y viceversa, a través de "biotas portátiles": "uma designação coletiva para os europeus e todos os organismos que eles carregaram consigo" (p. 280); alterando en forma definitiva la biodiversidad, el paisaje, los tipos y formas consuetudinarias de la producción agraria originaria en la región. Gran parte de este extenso

\footnotetext{
8 -La gestión compartida transnacional de su extenso territorio es imperativa, porque la Cuenca abarca territorio nacional de cinco países en la actualidad: Argentina, Paraguay, Brasil, Bolivia y Uruguay como se indicó antes aqui. Por ello, en 1969 se impulsó la creación del Tratado de la Cuenca del Plata siendo este uno de los antecedentes importantes del proceso de integración regional que desembocó en el Tratado de Asunción que en 1991 creó el MERCOSUR.

9 -Extraido de https://www.comip.org.ar/la-cuenca-del-plata/ Acceso en abril de 2020.

10 -lbidem.
} 
territorio sedió lo que hoy son apenas remanentes del Bosque Atlántico (Mata Atlântica). Sobre este ecosistema nativo, que ocupa fracción del área norte de la cuenca abarcando territorios de lo que es hoy sur de Brasil, nordeste de Argentina y oeste de Paraguay, gravitó con mayor fuerza la etapa colonial brasilera y hasta en el presente sus grandes ciudades, incluyendo una megalópolis, se encuentran emplazadas en dicho ecosistema.

Los intercambios tempranos entre pueblos originarios y portugueses en el inicio del siglo XVI, se hicieron bajo la forma del escambo de inmensas cantidades de pau Brasil y conforme Warren Dean (1996) eran cortados y hasta almacenados por los propios tupis a la espera de los portugueses, para ser intercambiados entre estos dos grupos a medida que los últimos avanzaban por el litoral hacia el sur: "Tratáva-se de uma madeira corante chamada ibirapitanga-árvore vermelha- pelos tupis, que com ela coloriam suas fibras de algodão. Os portugueses a chamavam de pau-brasil provavelmente a partir da brasa" (Dean,1996:63). En toda la obra de Dean que causó gran impacto y polémica entre ambientalistas sudamericanos se subraya que el impacto ecológico de la interacción humana con ese ecosistema se inició con los pueblos originarios antes de la llegada de los europeos y que contó con su ayuda a la llegada de los portugueses debido a la creencia errada que podría ser una fuente inagotable como describe en el "Capitulo 2" (pp38-58). Lo que cambió con los europeos según este autor fue la intensidad y velocidad de las transformaciones que se configuraron por ello, irreversibles. Luego de la instalación de los europeos, núcleos agro y primario-exportadores de la etapa colonial surgieron y crecieron a expensas de la Mata, procesos que intensificaron exponencialmente la huella ecológica que ya venían ocasionado otros grupos humanos antecesores en la ocupación intensiva de ese ecosistema. Después de más de 5 siglos de intensa ocupación los remanentes, significativos, aunque exiguos, de la
Mata Atlântica/Bosque Atlántico se encuentran actualmente en la Cuenca del Plata.

Una de las transformaciones más marcantes y duraderas tuvo que ver con la llegada del ganado. La introducción de vacunos, caballos, cerdos, ovejas y otros animales de granja asi como especies comestibles vegetales que se expandieron rápidamente crearon, en el caso de vacunos, con el transcurrir del tiempo grandes rebaños cimarrones, es decir, en estado salvaje y esparcidos por las llanuras fértiles a lo largo y ancho de las colonias iberoamericanas y especialmente en las llanuras de la Cuenca platense, alterando el paisaje de la cubierta vegetal en su búsqueda de pasturas ${ }^{11}$.

[...] procuraram trazer, para aclimatá-los desde as suas primeiras viagens, os animais que utilizavam em sua pátria, especialmente o cavalo, não só porque constituia o principal meio de transporte terrestre naqueles tempos, como também porque logo perceberam que era o cavalo [...]o nervo da guerra contra os nativos" (Reverbel, 1986, p. 28).

Inicialmente la organización productiva relativa al ganado consistió en apresar vacunos y caballos salvajes en rodeos rústicos: A pecuária nesta região pouco trabalho dá. O
gado é deixado à lei da natureza, nos pastos
em completa liberdade [...] O único cuidado
que reconhecem necessário é acostumar os
animais a ver os homens e a entender os seus
gritos a fim de que não fiquem completamente
selvagens [...].Para tal fim o gado é reunido de
tempos em tempos em determinado local,
onde fica durante alguns dias, depois voltando
para as pastagens, em liberdade. (Saint-Hilaire
apud Reverbel, 1986, p. 21).

Cuando esta fuente comenzó a agotarse, la estrategia pasó a ser la cría y engorde para consumo y especialmente para comercialización. La ganadería vacuna y mular conformó una de las actividades principales de las estancias rioplatenses, si bien en éstas coexistieron diversos tipos de producción como trigo ${ }^{12}$, maíz y otros cereales (Gelman y Garavaglia, 1995), así como el beneficio de la yerba mate, del tabaco y también

11 -Estos autores, como Crosby (2011) Dean (1996) entre otros; nos mencionan que el traslado e implantación de animales provenientes de otros ecosistemas allende los océanos para consumo y trabajo también implicó trasladar en muchos casos, las especies vegetales de las que se alimentaban e introducirlas en los ecosistemas nativos en desmedro de la flora y fauna local.

12 -Cereal también exótico, de origen asiático, introducido en las Américas por los europeos (Crosby, 2011). 
existieron estancias eminentemente madereras, combinando su producción para comercializar con la de diversos géneros alimenticios para consumo local como mandiocas y especies de zapallos, entre otros. También se caracterizaron, según su forma de administración, como religiosas $^{13}$ y laicas (Halperin Dongui, 1975)

En sentido contrario y a la manera de una resistencia cultural ambientalmente posibilitada la ilex paraguariensis ${ }^{14}$, árbol de la yerba mate seleccionado en el medio natural para el consumo por parte de los guaraníes como bebida refrescante y ritual, consumida como una infusión en un cuenco (cuia) también extraído de un fruto vegetal (lagenaria siceraria) y absorbido con una bombilla inicialmente también vegetal ${ }^{15}$, fue adoptada por los ibéricos aun superando iniciales resistencias de los clérigos y autoridades imperiales ${ }^{16}$. Inicialmente la práctica de beber mate estuvo cuestionada y hasta penalizada con multas, azotes y cárcel.

[...] la yerba debió entablar una dura batalla para imponerse ante los celosos defensores de la moral que la atacaron desde temprano con todo un arsenal represivo [...] De esta forma comienzan a encadenarse las disposiciones prohibitivas. La primera que conocemos es la dictada por Hernandarias en 1596 y que fulmina con 10 pesos de multa y 15 días de cárcel a quien fuese sorprendido bebiendo yerba. Unos años más tarde Diego de Torres reclama airadamente al Santo Oficio de la Inquisición; las excomuniones no tardan en llegar [...] (Garavaglia, 2008, p. 48-49).

A pesar de los esfuerzos de los jesuitas desde mediados del siglo XVII por extender su consumo por fuera de ecosistema de origen, buscando así crear un gigantesco mercado interno en los demás virreinatos españoles; si bien tuvo una gran expansión en su consumo desde el espacio de las misiones jesuíticas hacia el espacio alto-peruano en los siglos XVII y XVIII (Garavaglia, 2008) la práctica del beber el mate a la manera guaraní, con cuenco y bombilla-más allá del grupo étnico al que se pertenezca- estuvo y sigue estando restringida territorialmente a los límites de la región histórico-ambiental de la yerba mate y de los distintos pueblos guaranies que la seleccionaron para su uso cotidiano entre lo disponible en su hábitat. En la contemporaneidad su consumo a la manera guarani17: mate (cuia) agua y bombilla sigue restringida dentro de sus fronteras histórico-ambientales, a diferencia del tabaco otro consumo y cultivo americano, que sin embargo sí consiguió extrapolar su ambiente originario para ser consumido globalmente.

Y es en el conocimiento de los procesos histórico-agrarios regionales, por caso sobre la yerba mate, donde podemos percibir que una planta, ilex paraguariensis, perteneciente a un ecosistema específico, seleccionada para su uso por habitantes milenarios, la "nación guarani"18, puede por sí misma explicar gran parte de la historia colonial del Paraguay: "La yerba mate fue por mucho tiempo el principal producto de exportación del Paraguay, inclusive después que los jesuitas del sur, se apoderaron con éxito del mercado con cosechas cultivadas en los siglos diecisiete y die-

\footnotetext{
13 -Diversas órdenes religiosas gestionaron la producción en la forma de estancias en este territorio analizado y en otras regiones iberoamericanas. Las órdenes religiosas adoptaron y gestionaron las formas de producción ambientalmente posibles en cada región como por ejemplo en la región nor-hispana gestionaron haciendas (cf. Riley, 1975).

14 -Planta umbrófila que crecía por asociación, en su forma salvaje, a la sombra de las araucarias en la Mata/Selva Atlántica y por ello eran llamadas de "plantas hermanas" por los guaranies (Hueblin, 2011, p.12)

15 - Luego suplantada por una bombilla de metal cuando los europeos comenzaron a consumir el mate en el periodo colonial, ya que soportaba mejor el agua caliente que es la forma con la que se prepara el mate hasta nuestros dias y facilitó el traslado del hábito del mate a otras geografias de los dominios imperiales en cuyos ecosistemas no conseguian elementos de la naturaleza que pudieran usarse como bombilla. (Garavaglia, 2008)

16 -Si bien en el Paraguay actual predomina el tereré una versión con agua fria originaria y agregando a la yerba mate algunas hierbas refrescantes, aromáticas o medicinales.

17 - Una de las formas para que los europeos no usen la bombilla al beber el mate, hábito considerado inmoral y repugnante por algunos, fue colocarla en saquitos de té para beberla a la manera "civilizada". Esa transformación para ser bebida en infusión individual fue implementada por los jesuitas buscando expandir su floreciente mercado más allá de la región histórica natural. Por ello lo que hoy se llama "mate cocido" en la parte hispanohablante de la cuenca en esa etapa se conoció como "té de los jesuitas" (Garavaglia 2008).Caracteristicamente es la forma que actualmente es aceptada como bebida "exótica" en otras partes del mundo dado que la resistencia a compartir la bombilla todavía sigue presente solo que ahora con argumentos higienistas y hasta médicos adjudicándole a la práctica de beber el mate con agua caliente una incidencia directa en cánceres del sistema digestivo. El carácter convivial, de reunión, depende de compartir el mate a través de la misma bombilla y eso también está colocado en entredicho en las medidas de prevención de contagio del COVID-19 en la pandemia actual. Otra vez está penalizada su convivialidad.

18 -Aquí el concepto de "nación" se adscribe a los elementos étnico-lingüísticos compartidos en un territorio determinado.
} 
ciocho" (Cooney, 2006:38). Asi como nos muestra el despliegue de una forma de comercialización regional que no se detenía en fronteras administrativas imperiales impulsada por un consumo que también las ignoraba, ya que se consumia por indígenas, criollos y europeos- tanto del espacio luso como hispano colonial de la región norte de la Cuenca- llegando de ese modo hasta nuestros dias enlazando nacionalidades, etnias y lenguas.

Por todo esto, podemos ver en el caso de la yerba mate y en la práctica de beber el mate, como las regiones histórico-ambientales imponen su estructural influencia sobre la temporalidad coyuntural (tiempo corto) y sobre la diversidad de los procesos autorreferencialmente humanos. El cultivo con fines de comercialización de la yerba mate fue una actividad colonial organizada sobre una planta seleccionada anteriormente para uso humano por los guaranies (Garavaglia, 2008) posteriormente adoptada por aquellos que llegaron a estos territorios durante el siglo XIX, especialmente desde la segunda mitad, en grandes oleadas migratorias también europeas y también del Lejano y Cercano Oriente. Notablemente son esos descendientes de europeos, mayoritariamente mediterráneos y de la región central, quienes una vez instalados en Estados del Sur de Brasil adoptaron fervorosamente el chimarrão y la denominación identitaria gaúcha en su sentido histórico de vocación y cultura rurales, asociado al pasado estancieiro pero desprovisto el primero de esos elementos de su genealogía étnica originaria. Lo que desde algún punto de vista también podria pensarse como apropiación cultural.

Las estancias ganaderas coexistieron con las yerbateras y de tipos productivos combinados en la pequeña producción familiar criolla y orientados al mercado interno regional como ya se mencionó, siendo paradigmáticas al norte de la Cuenca las estancias yerbateras de las que da cuenta Garavaglia (2008) en coexistencia con las estancias ganaderas y los saladeros. Hacia el sur son más caracteristicas las estancias ganaderas y mulares (Halperin Donghi,
1975: Giberti, 1970) existiendo también pequeñas unidades familiares de producción ${ }^{19}$, campesinado criollo y libre, en todo el espacio demarcado para este análisis que combinaban producción de cereales y otros productos agrícolas como la mandioca, otro producto típico de la agricultura guarani, destinado al consumo alimentario en la región (Garavaglia y Gelman, 1995).

Si para Braudel "o Mediterrâneo equilibra sua vida a partir da triade oliveira, vinha e trigo" (Braudel,1985, p. 25) la Cuenca del Plata lo hará, más allá de lenguas y culturas milenariamente preexistentes, desde la etapa colonial en adelante a partir de la yerba mate, la carne bovina y la mandioca.

\section{La centralidad de la estancia}

Hacia inicios del Siglo XIX, durante y posteriormente los procesos de independencias de las colonias tanto del área portuguesa como española, las estancias consolidarán el rol de proveedoras de carnes, cueros, yerba y otros géneros alimenticios para abastecer las demandas del mercado interno regional (Garavaglia, 2008). En algunos casos como en la Provincia de Buenos Aires desenvuelven una anticipada vinculación con los mercados externos a través de exportaciones vía puerto de cueros y grasas (Halperin Donghi, 1975). Las exportaciones de la producción ganadera de las estancias devenidas en charqueadas o saladeros no tendrian, sin embargo, el peso económico y por ende político para las administraciones centrales que tuvieron por ejemplo las fazendas en la economía de plantación exportando azúcary café posteriormente en el contexto imperial luso-brasileño e incluso las haciendas en el escenario colonial nor-hispano (Mörner, 1975).

Las estancias, además, se caracterizarian por la coexistencia de una temprana y relativa asalarización de sus relaciones laborales (Halperin Donghi, 1975) debido a la escasa población existente en tales territorios con prácticas esclavistas. Asalarización que no debe ser entendida en los términos actuales, ya que el pago muchas veces se estable-

19 -Palacios (1998) en su Cultivadores libres, Estado y crisis de la esclavitud en Brasil en la época de la Revolución industrial, publica los resultados de su investigación enfocándose precisamente en la coexistencia de estas formas de pequeña producción familiar de campesinos pobres y libres que gravitaban alrededor de la plantación esclavista en la Capitania de Pernambuco en los siglos XVII y XVIII; mostrando hasta qué punto alrededor de las formas paradigmáticas de la organización de la producción agraria existía una agro-socio-diversidad. 
cía nominalmente ${ }^{20}$ y con diversos mecanismos de sujeción de los trabajadores por deudas contraídas por el suministro de alimentos básicos realizado por los propios patrones a precios exorbitantes y descontados de sus "salarios", cuestión que fue común también en las haciendas ganaderas otras regiones hispanoamericanas (Mörner, 1975).

En la "Provincia del Paraguay" muchas estancias utilizaron también mano de obra esclava tanto indígena como de origen africano (Maestri,2016), a partir de la extensa y conturbada vigencia de la encomienda como sistema que hizo de la esclavitud indígena-incluso en estancias yerbateras- su forma de gestión más habitual en la producción agraria desde el siglo XVI, abolidas legalmente hacia el siglo XVIII, pero entrando hasta principios de siglo XIX en su vigencia:

Fundada en 1556 por Domingos Martínez de Irala como sistema por medio del cual los españoles podian regularmente exigir tributo en forma de servicios laborales a los habitantes guaranies de la Región del Alto Plata, la encomienda hispano indígena siguió un patrón que es familiar para los estudiosos de las relaciones hispano-indigenas: drástica despoblación en los pueblos indigenas ${ }^{21}$, estancamiento demográfico, rápida aparición de una población de mestizos, leyes humanitarias españolas promulgadas para proteger a los indios de la codicia de los colonos y persistente evasión de estas leyes por los primeros encomenderos españoles y luego por los paraguayos criollos (Saeger, 2006, p. 65).

La utilización de personas reducidas a esclavitud fue maciza en las estancias ganaderas riograndenses, no solo en estancias de cría de ganado y las yerbateras en menor medida, sino también en los saladeros y charqueadas extendiéndose durante la mayor parte del Siglo XIX aun con la disrupción política que significó la Revolução Farroupilha a mediados de ese siglo:

Em 1820, ao entrar no Rio Grande do Sul pelo litoral, percorrendo o caminho onde se estabeleceram as primeiras estâncias luso-brasi- leiras, Saint-Hilaire deteve-se na fazenda do barão de Santo Amaro, onde estava sendo instalado grande curtume, com o emprego de 80 escravos [...] (Reverbel, 1986, p. 22)

La presencia de las estancias en el amplio territorio, además de ser la condición de posibilidad de la existencia y el sostenimiento de las ciudades, y no a la inversa, expresaria una estructura social típica de sociedades pastoriles o en el caso paraguayo campesinas Maestri (2016). La creación de las llamadas "estancias de la patria" administradas por el Estado 22 por iniciativa del líder independentista paraguayo José Gaspar Rodriguez de Francia y Velazco (1766-1840)-apodado Karai Guazu- es muy elocuente en ese sentido:" Las Estancias de la Patria se localizaban principalmente en el Paraguay Oriental:

\begin{abstract}
tuvieron sus origenes en las propiedades de la Compañia de Jesús, transferidas al Estado después de la expulsión de la Orden en 1767, a las cuales se sumaron las propiedades incorporadas, sobre todo a través de la expropiación de propietarios envueltos en conspiraciones antifrancistas [...] cuidadosamente administradas producian ganado para la alimentación del Ejército y cueros para uso interno y pequeña importación. Eventualmente, ellas abastecian alimentos para la población pobre. (Maestri, 2016, p. 159).
\end{abstract}

Tomando en cuenta las características de la organización de los factores de poder politico tal vez sea útil descentrar la idea que subraya Chiaramonte (2004), que en la etapa apenas las ciudades habrian rivalizado entre sí constituyéndose en focos de insurgencias y de disputa política, minimizando la importancia del mundo rural como protagonista de la vida política local, para contraponerse a una historiografía doméstica "tradicional" que resalta la ruralización del poder político americano pre y postindependentista. Es una tentación muy europeizada, finalmente, la adscripción del poder político a lo urbano, en un periodo como el analizado aquí.

\footnotetext{
20 -Garavaglia (2008) menciona que en el espacio rioplatense el dinero en forma física era bastante raro de ver para la etapa. Transacciones y operaciones se hacian principalmente en especies y llevando un registro de valor monetario nominal de respaldo.

21 - Jared Diamond, en su instigante libro Armas, gérmenes y acero (1986), demuestra el rol preponderante que tuvo el contacto entre los cuerpos y del intercambio de gérmenes con saldo desfavorable para los indigenas, lo cual aunado con cambios drásticos en la alimentación, en los ritmos de trabajo y descanso, causó epidemias constantes que diezmaron la población indigena de forma irreversible. 22 -Este autor también menciona que otras estancias de propiedad del Estado eran entregadas en arriendo a particulares a precios reducidos." Eran formadas por campos de cultivo, campos de cria, bosques ricos en yerba mate y en madera, principales productos paraguayos de exportación" (op.cit.)
} 
Este diversificado sistema de estancias en la Cuenca del Plata, con diversas tipologías según los indicadores que se tomen, comparten sin embargo el factor común de ser una forma nueva, ambientalmente posibilitada también, en relación a la organización productiva agraria de pueblos originarios de la región.

\subsection{Estancieros y conflictividad politico- territorial}

La primera mitad del siglo XIX, es un periodo de gran complejidad en toda el área colonial americana y especialmente en la Cuenca del Río de la Plata. Chiaramonte (2004) señala las dificultades para aproximarse a las entidades políticas en gestación una vez desplazadas las monarquías ibéricas en la región. El autor se interroga acerca de la "naturaleza" de las entidades políticas que cubrieron el vacío de poder desde la desaparición del vínculo monárquico en la Hispanoamérica meridional. En el caso brasileño, la desvinculación de la monarquía portuguesa dio lugar al Imperio Brasilero desde 1822 conducido también por integrantes de la Casa de Bragança e Orleans, Pedro I y María Leopoldina de Austria su cónyuge y máxima jefa política reemplazante en ocasiones ${ }^{23}$. Traspaso de manos en el podery de continuidad monárquico-imperial resistida en varios puntos del territorio, ya que se produjeron a lo largo de la primera mitad del siglo revoluciones secesionistas no solo respecto de Portugal sino también del propio Imperio Brasilero que lo sucede, especialmente en el Periodo Regencial (1831-1840) y con la manifiesta decisión de formar repúblicas y confederaciones de estas, en una analogía con la dispersión de los centros de poder que siguió a la desvinculación con la metrópolis en el ámbito hispano-americano.

En ese sentido, la Revolução das Farroupilhas (1835-1845) que desembocó en la proclamación de la República de Piratini o República Riogranden$s e^{24}$, podría contribuir a una interpretación distinta respecto de la forma en que se tejen alianzas de "soberanías" basadas en "afecciones locales" de ciudades y provincias del mismo contexto ambiental platense, con parecidas pretensiones de constituirse en Repúblicas y desechando otras formas de organización política como las monarquías.

\begin{abstract}
Desligado o povo riograndense da Comunhão Brasileira, reassume todos os direitos da primitiva liberdade; usa destes direitos imprescritiveis constituindo-se República Independente: toma na extensa escala dos Estados Soberanos o lugar que the compete pela eficiência de seus recursos, civilização e naturais riquezas que lhe asseguram Soberania e Domínio, sem sujeição ou sacrificio da mais pequena parte desta mesma Independência ou Soberania a outra Nação, Governo ou Potência estranha qualquer. Piratini, 29 de agosto de 1838. (Spalding, 1963, p.332)
\end{abstract}

Precisamente, de los reparos que hace Chiaramonte (2004) a la práctica de la historiografia política convencional de adjudicar a los movimientos independentistas platenses de la primera mitad del siglo XIX una intencionalidad de construcción de una nacionalidad ${ }^{25}$, cuando no su propia motivación (p. 20) es que surge la posibilidad de repensar para la etapa en perspectiva ambiental, si bien el autor no manifiesta esa preocupación. Por otro lado, es realmente difícil concordar con su propuesta de categorizar estas expresiones políticas territorializadas como "cuerpos políticos intermedios" (p. 63) con tanta declaración de independencia y conflictos secesionistas en territorios que de inmediato se proclamaron como Repúblicas independientes, se dictaron una Constitución y hasta eligieron presidente como por ejemplo Bento Gonçalves da Silva, estanciero y militar, entre 1837 y 1845 en la Republica de Piratini.

Como amalgama que delimita los contornos de esas formaciones políticas del periodo pre y post independencia, donde pueblos, ciudades y campañas rurales se posicionaron para reclamar autonomías, independencias y establecieron confederaciones; podria inferirse que uno de los principales factores identitarios, constituyentes de esos "nosotros" platinos, estarian basados en ese

\footnotetext{
23 -La historiografía política brasilera coloca a los hacenderos como fuerzas políticas de enorme gravitación en tales acontecimientos.

24 -Las ideas, en los inicios de las revoluciones independentistas del mundo sur-hispano, de recrear o anexarse a monarquias ya existentes tuvo más que ver con las elites urbanas de ciudades puertos, como Buenos Aires, por ejemplo.

25 -Todavía hoy en el Estado de Rio Grande do Sul se celebra oficialmente el día de la Declaración de la Independencia Farroupilha.
} 
sentido de pertenencia común, ambientalmente sustentado, que el autor llama de forma vaga como "afección local" (p. 14) que se desprendería del examen documental de fuentes primarias que realiza para sus investigaciones.

Los conflictos armados en la región de la Cuenca del Plata, posteriores a las declaraciones de independencias, fueron durante la primera mitad del Siglo XIX, eminentemente conflictos rurales, protagonizados por estancieros que en muchos casos tenian un proyecto político claro, que incluía alianzas con otros liderazgos de similar fragua más allá de un pasado colonial, ora español ora portugués (Moniz Bandeira, 2012) como es el caso del liderazgo regional del estanciero oriental José Gervasio de Artigas (1764-1850), temprano proyecto político de integración platina derrotado esencialmente por el liberalismo portuario del sur de la cuenca:

Com a derrota da etapa artiguista do processo de descolonização do Uruguai não só foi vencida a etapa radicalizada da revolução, mas foram vencidas as massas de pequenos proprietários, posseiros, gaúchos, peões, índios, mulatos, etc; que eram a base do projeto de Artigas. Esse projeto reformista, no referente à construção do Estado, visava a integração do QuadriláteroUruguai, Missões (incluindo as brasileiras, Entre Rios e Corrientes. (Piccolo, 1985, p. 35).

Así también, otros caudillos de origen estanciero que ejercen también funciones militares con tropas propias, un "curriculum" común en los liderazgos de la región en el periodo, mantenian aspiraciones "regionalizantes". Como por ejemplo el también oriental y estanciero José Fructoso Rivera (1784-1854) a quien también se atribuye la idea de "formar um grande Estado Federativo que incluía o Rio Grande do Sul" (Piccolo, 1985, p. 50). El propio conflicto secesionista riograndense llevó a una intensificación, no carente de conflictividad, de las relaciones comerciales y políticas entre estancieros "nor-platinos". Es decir, entre estancieros que hoy denominariamos argentinos, brasileros, paraguayos y uruguayos (Piccolo, 1985)

Aunque Chiaramonte (2004) rechaza la definición de "proto-estados" que utiliza, por ejemplo, Moniz Bandeira (2012) para caracterizar estas formaciones politicas en el periodo que transcurre entre las independencias y la formalización de los atributos materiales y simbólicos que definen a los Estados Nacionales, logrados en la región apenas hacia el final del siglo XIX, es incuestionable que lideres de los territorios a lo largo y ancho de la cuenca, que a su vez son estancieros y/o saladeristas en la mayoría de los casos, están posicionando sus aspiraciones insurgentes en un tipo especifico de Estado que es la República. Esto es claro en el proyecto político de Artigas en la Banda Oriental y con gran influencia en casi toda la Cuenca, incluyendo a los lideres de las insurgencias del sur de Brasil- estancieiros, charqueadores y saladeiristas-que no solo aspiran sino que establecen por la vía revolucionaria formas políticas denominadas Repúblicas, siendo la experiencia riograndense la más exitosa y duradera de ellas en el sur del actual Brasil- pero no la única ${ }^{26}$-que duró nada menos que 10 años, hasta que fue sofocada por la vía militar, previo sofoco comercial según Moniz Bandeira (2012) reincorporándose al Imperio Brasilero.

Otra característica marcante de la ecorregión histórica analizada, es la superposición, inestabilidad y fragmentación de jurisdicciones, creando fronteras tan móviles y cuestionadas, desde el propio Tratado de Tordesillas y los que le siguieron, promoviendo asi que la identidad del Cono sur sur-americano sea más influenciada por la "personalidad" ambiental, elemento más fijo y estable que los pactos administrativos imperiales y pos-independentistas. De allí la insuficiencia, más percibida que explicitada en la historiografía tradicional, de las explicaciones adscriptas a teorías políticas y a agendas historiográficas nacionales apenas.

a compreensão da Guerra dos Farrapos no
seu sentido de questionar o Estado Nacional
como esse vinha sendo construido passa pelo
discurso liberal limitado na sua elaboração
nas relações sociais e dominação vigente na
formação social do Rio Grande do Sul-formação
essa indissociada dos problemas decorrentes
da situação fronteiriça da província, que por sua
vez estão imbricados na formação dos Estados
Nacionais platinos (Landgraf Piccolo, 1985, p. 59). 
El ambiente platense sigue allí, dejando ver la amplitud regional y transnacional de su marca, más desde lo tácito que lo expresado. Dicho complejo eco-histórico-cultural tendria para la etapa un rol de espacio "nuevo", poco poblado y abundante, menos biodiverso, posibilitando por ello liderazgos más advenedizos que aquellos de las regiones coloniales precedidas por estructuras sociales estratificadas, de gran centralización administrativa, fuerte demografía y consolidadas formas de organización productiva que sostuvieron antiguas y muy pobladas ciudades desde el periodo precolombino en otros ecosistemas sur americanos como el andino. Este camino "agro-político" hacia la constitución de los Estados Nacionales, en cada territorio postcolonial iberoamericano: ¿estaría influenciado por los condicionantes ambientales en sus diferenciaciones respecto a las formaciones políticas de otros ecosistemas coloniales?

En un ambiente específico, lo que posibilita o restringe la forma de producción agraria- tanto como estrategia comercial como de sustento para la materialidad de la vida- así como de la propia organización social comunitaria, brindaria un sentido de pertenencia a algo inmediato y concreto, más palpable que abstracciones como imperios y repúblicas en la cotidianeidad de las vidas efectivamente vividas, especialmente cuando estas abstracciones políticas centralizantes se materializan apenas para requerimientos tributarios y leva de tropas compulsorias para guerras lejanas.

Fueron las estancias los núcleos de acción política y de la organización social y cultural durante largos siglos en la región. Del análisis de la literatura de referencia para el tema, surge la convicción que las revoluciones independentistas en la Cuenca del Plata a lo largo del XIX, tanto las que tuvieron éxito como las que no, fueron agremiaciones inestables de intereses estancieros, domésticos y regionales, ante monarquías centralizadoras y siempre hambrientas de sus recursos.

\section{El gaucho como arquetipo estanciero}

El arquetipo emergente de la estructura social estanciera es el gaucho platino y su equivalente el gaúcho brasilero ${ }^{27}$ :

Os primeiros rebanhos entraram no Rio Grande do Sul pelo Alto Uruguai, na região missioneira. Começava a formar-se o casco dos grandes rebanhos de gado chimarrão ou alçado, em cujo ambiente começaria a despontar, na medida em que se caracterizava a idade do couro, o tipo social que se encarnaria na figura do gaúcho. (Reverbel, 1986, p. 24).

Aun cuando Gelman (1987) menciona que su gravitación como trabajador rural ganadero en el periodo es más mítico que real, su construcción literaria y el fuerte sesgo identitario que todavía conserva en la región sur de Brasil, denominada região gaúcha, especialmente en Rio Grande do Sul, nos permitió evidenciar los elementos ambientales que se tomaron en cuenta en su construcción idealizada según algunos, pero significativa en todo caso.

La obra literaria argentina El gaucho Martín Fierro de José Hernández (1897) ${ }^{28}$ conocido por la mayoría de la clase (turma) fue utilizada como estrategia didáctica en la Disciplina para reconocer los elementos ambientales en la caracterización. La tarea se hizo sencilla: el paisaje, la amplitud territorial, la poco densa población asentada en él y los condicionantes ambientales vividos como fortalezas y posibilidades de libertad por el protagonista y otros co- partícipes recorre toda la obra, reflejando también aspectos demográficos y de

\footnotetext{
27 -Y por analogía podriamos incorporar al cowboy norteamericano dentro de los arquetipos emergentes del complejo eco-bio-cultural resultante de las transformaciones del paisaje provocadas en la colonización europea de las Américas, debido a la introducción por parte de la colonización ibérica del ganado bovino, equino y de otras especies menos gravitantes en la etapa en todos sus dominios y que pronto extrapolaron sus fronteras administrativas. Quizás las diferencias más significativas entre gauchos, gaúchos y cowboys sea la más temprana "democratización" de las armas de fuego entre los últimos. La versión sudamericana se diferenciaba por la dieta-el mate amargo, por ejemplo- y por diferencias tecnológicas en su armamento defensivo: los gauchos/gaúchos estaban armados predominantemente a cuchillo. Mas al sur incorporaron armamento defensivo de pueblos originarios del lugar como por ejemplo las boleadoras. Los aguardientes, existían en todos los ecosistemas antes y después de la invasión europea: al whisky del cowboy le correspondia por aqui la caña. Y los pueblos originarios tenian los propios.

28 - Una de las obras cumbre de la literatura brasilera, equivalente a la importancia que se le da en el sistema educativo argentino a la obra de Hernández, es Os sertões. Campanha de Canudos de Euclides da Cunha (1902) de quien podría decirse coloca al ambiente como protagonista de una narrativa dejando como actor secundario a un sangriento conflicto agrario, la Guerra de Canudos acontecido hacia finales del siglo XIX en el nor-oeste del país.
} 
ocupación del espacio así como, esencialmente, formas de producción agraria y dieta válidos para comparar con lo expuesto por la literatura científica sobre esos temas para el periodo: "o cavalo, o mate amargo e a carne assada nas brasas (churrasco) constituem os elementos característicos do complexo cultural gaúcho" (Reverbel 1986, p. 37). El cavallo de origen asiático, es introducido también en las Américas por los conquistadores europeos, pero fundamentalmente como arma de guerra (Reverbel, 1986) contra la resistencia de los nativos y pronto es apropiado por los vencidos para resistirlos. Para el gaucho, el caballo es una herramienta de trabajo y fundamentalmente su medio de libertad y autonomía como se desprende del análisis de las obras literarias utilizadas en la estrategia didáctica mencionada.

El enfoque interdisciplinario permitió incorporar perspectivas transversales de corrientes epistemológicas surgidas en las últimas décadas en el marco de los diversos "ecologismos" como por ejemplo sacar a la luz del debate áulico el paralelismo entre el silenciamiento del ambiente, la subordinación de la naturaleza al poder transformador humano y en especial la masculinización de tales ideas, formas de hacer y arquetipos ${ }^{29}$ en la historiografía tradicional.

En la Historiografía tradicional, agraria o no, sobre la Cuenca del Plata el ambiente está tan ausente o subordinado al hacer de los hombres como las mujeres. Las mujeres son poco mencionadas en la historiografía tradicional y aun menos en la historia agraria ${ }^{30}$. Por ejemplo, analizando la literatura gauchesca como fuente, vemos que las mujeres aparecen como condición de posibilidad de la existencia misma del gaucho, como trofeo a conquistar, pero a la vez son temidas, en analogía con las percepciones sobre la naturaleza. Ellas existen sólo como respuestas para necesidades humanas, pero su protagonismo social y político en el periodo no es recuperado con la misma fuerza que los personajes fuertemente masculinizados del estanciero, del caudillo y del gaucho. Gran parte de la producción de conocimiento sobre "lo agrario" conserva esa impronta de masculinización hasta nuestros dias.

\section{Conclusiones}

Las formas de producción agraria, ambientalmente posibilitadas, se expresan en formas de organización social y política caracterizando profundas y duraderas diferencias regionales en la formación de los Estados Nacionales, creando identidades territoriales singulares en las distintas sociedades y grupos étnicos que conviven con ese ambiente especifico. El ambiente posibilita, conflictúa el acontecer humano y a la vez lo caracteriza, es decir lo dota de una personalidad cultural territorialmente condicionada.

Dar significación a la región histórica que contiene el espacio geográfico donde está emplazada la universidad, desde las renovaciones que propone la Historia Ambiental en Disciplinas vinculadas a la enseñanza de la Historia de América Latina como la de Historia Rural y Agrária latino-americana fue una apuesta epistemológica y pedagógica exigente para conseguir la reunión de tanta diversidad en la comprensión de la cultura ambientalmente condicionada en el escenario amplio, transnacional pero concreto como lo es la Triple Frontera del Paraná donde transcurren vidas cotidianas y universitarias en un continuum. Pocas razones duraderas como la misma idea de ambiente, permiten crear un sentido de integración y pertenencia que ultrapasa los tabiques de las fronteras nacionales y la identificación con las características geo-bio-culturales de ecosistemas, resisten con sus improntas identitarias a la transformación antrópica que se percibe como muy acelerada y devastadora en el presente.

Vale la pena por ello rastrear en las etapas pretéritas más representativas de las abruptas trans-

\footnotetext{
29 -En este caso regional, la reflexión de Vandana Shiva (2004) economista y eco-feminista hindú, cuando dice que el hombre blanco trata a la naturaleza como trata a las mujeres (p.9) es decir en forma instrumental, subordinada y muchas veces predatoria, podría relativizarse porque en la Cuenca del Plata el gaucho, que no era blanco, las trató del mismo modo según lo que expresa la literatura.

30 -El marxismo latino-americano tan influyente en la Historia Agraria latino-americana y en los estudios rurales en general solo dialogó por décadas entre referentes hombres. Recién a partir de los 80 del siglo XX comienzan a ser recuperadas en los circuitos de reconocimiento académico las historiadoras agrarias. Aunque su presencia no signifique necesariamente visibilizar a las mujeres como sujetos de la Historia en los procesos que estudien y narren.
} 
formaciones ecológicas producidas en nuestro ambiente, para aprender de su devenir temporal que la producción de alimentos y energía sobre una base agraria, así como las vicisitudes de la convivencia humana misma, precisan tomar en cuenta diacrónicamente al ambiente, no solo en cuanto actor coprotagónico, sino en las interacciones mismas que se producen entre las actividades humanas y lo no humano, en transformación mutua.

La construcción de identidades territoriales ambientalmente posibilitadas formadas en este periodo alrededor de la centralidad de la estancia como forma de producción agraria y también productora de sentidos simbólico, se proyectaron largamente en el tiempo y en el espacio, dentro de los limites histórico-ambientales que superan las fronteras políticas nacidas en el periodo, en la forma de tradiciones nacionales en estas nacientes repúblicas que fueron materializando identidades nacionales y lingüisticas divergentes pero subordinadas a una identidad ambiental común.

Este complejo proceso encuentra un final en la sustitución significativa por elementos nuevos propiciados por la Revolución Verde, llegada a la región promediando el siglo $\mathrm{XX}$, que conforman actuales identidades predominantes debido a su potencia para desestructurar y reestructurar la organización del espacio rural agrario y sus relaciones histórico-ambientales consecuentes en la Cuenca del Plata; como otrora lo hiciera la estancia. Si la era de las estancias fue un momento de adaptación a las circunstancias ambientales en la colonización ibérica de la Cuenca, la Revolución Verde inauguró una fase más volcada al posibilismo antropocéntrico, cuyos límites ya se hacen ver en nuestros días.

\section{Bibliografía}

BRAUDEL, Fernand. O Espaço e a História no Mediterrâneo. Trad. Marina Appenzeller. São Paulo: Editora Martins Fontes, 1988.

CASTRO HERRERA, Guillermo. De civilización y naturaleza: notas para el debate sobre historia ambiental latinoamericana. Procesos, Revista Ecuatoriana de Historia, [S. L.], n. 20, p. 99-113, 2004. https://doi.org/10.29078/rp.v1i20.251.

CHIARAMONTE, José Carlos. Nación y Estado en Iberoamérica. El lenguaje politico en tiempos de las independencias. Buenos Aires: Editorial Sudamericana, 2004.
$\mathrm{CHONCHOL}$, Jacques. Sistemas agrarios en América Latina. De la etapa pre-hispánica a la modernización conservadora. Santiago: Fondo de Cultura Económica, 1996.

COONEY, Jerry. Los yerbales del norte: la explotación de la frontera del Paraguay,1776-1810. In: WHIGHAM, Thomas L.; COONEY, Jerry W. (ed.). Campo y frontera. El Paraguay al fin de la era colonial. Asunción: Servilibro, 2006.

CROSBY, Alfred. Imperialismo ecológico. A expansão biológica da Europa 900-1900. São Paulo: Editora Schwarcz, 2011

DIAMOND, Jared. Armas, germes e aço: os destinos das sociedades humanas. São Paulo: Editorial Record, 2017. Edição comemorativa.

DEAN, Warren. A ferro e fogo: a história da devastação da Mata Atlântica Brasileira. São Paulo: Companhia das Letras, 1996.

DONGHI, Tulio Halperin. Una estancia en la campaña de Buenos Aires: Fontezuela. In: FLORESCANO, Enrique (org.). Hacienda, latifundios y plantaciones en América Latina. Simposio de Roma. México: Siglo XXI Editores, 1975.

GARAVAGLIA, Juan Carlos; GELMAN Jorge. Rural history of the Rio de la Plata 1600-1850. Results of a historiographical renaissance. Latin American Research Review, [S. l.], v. 30, n. 3, p. 75-105, 1995

GARAVAGLIA, Juan Carlos. Mercado interno y economía colonial: Tres siglos de historia de la yerba mate. Rosario: Prohistoria Ediciones, 2008.

GELMAN, Jorge. Una historia dada vuelta. Los aportes de Carlos Sempat Assadourian a la historia económica y agraria rioplatense. Revista Nuevo mundo, mundos nuevos. 2012. DOI: https://doi.org/10.4000/nuevomundo.64714. Disponible en: https://journals.openedition. org/nuevomundo/64714. Acceso: 3 abr. 2020. https:// doi.org/10.4000/nuevomundo.64714.

GELMAN, Jorge. Rosas, estanciero: gobierno y expansión ganadera. Buenos Aires: Claves para todos, 2005.

GELMAN, Jorge. Gauchos o campesinos? Anuario IHES N.2. Buenos Aires: UBA,1987.

HERNANDEZ, José. El gaúcho Martin Fierro. Buenos Aires: Imprenta de la pampa, 1872.

HUEBLIN, Hans Jorg. Sistemas de aproveitamento integral da biomassa de árvores de reflorestamento. Dissertação (Mestrado) -- CEFET, Curitiba, 2001.

LEFF, Enrique. Construindo a História Ambiental na América Latina. Apresentado em 14 de jul. 2003. Texto da Conferência proferida no $51^{\circ}$ Congresso Internacional de Americanistas, Simpósio de História Ambiental Americana, de 14 a 18 de julho de 2003. Realizado em Santiago, Chile.

LE ROY LADOURIE, Emmanuel. História dos Camponeses Franceses Vol. 1: da Peste Negra à Revolução. Rio de Janeiro: Civilização Brasileira, 2007.

MAESTRI, Mário. Paraguay, la República campesina 1810-1865. Asunción: Editora Intercontinental, 2016. 
MONIZ BANDEIRA, Luiz. A expansão do Brasil e a formação dos Estados na Bacia do Prata. Argentina, Uruguai e Paraguai. Rio de Janeiro: Civilização brasileira, 2012.

MÖRNER, Magnus. La hacienda hispanoamericana. Examen de las investigaciones y debates recientes. In: FLORESCANO, Enrique (org.). Hacienda, latifundios y plantaciones en América Latina. Simposio de Roma. México: Siglo XXI Editores, 1975.

NEVES, Erivaldo Fagundes. História Agrária e História Regional na Perspectiva Sócio-Económica. Anais Eletrônicos II Encontro Estadual de História. Bahia ANPUH. Feira de Santana: Universidade Estadual de Feira de Santana, 2004. Disponible en: http://www.uesb.br/ anpuhba/artigos/anpuh_II/erivaldo_fagundes_neves. pdf. Acceso en 3 abril 2020.

PALACIOS, Guillermo. Cultivadores libres, Estado y crisis de la esclavitud en Brasil en la época de la Revolución industrial. México: Fondo de Cultura Económica, 1998.

PICCOLO, Helga. A guerra dos Farrapos e a construção do estado nacional. In: PESAVENTO, Sandra et.al. (Org.) A Revolução Farroupilha: história \& interpretação. Porto Alegre: Mercado Aberto Edições, 1985.

PRIGOGINE, Ilya. La estructura de lo complejo. Madrid: Alianza Editorial, 1994.

REVERBEL, Carlos. O gaúcho. Aspectos da sua formação no Rio Grande e no Rio da Prata. Porto Alegre: L\&PM Editores Ltda, 1986.

RILEY, James. Santa Lucia. Desarrollo y administración de una hacienda jesuita en el siglo XVIII. In: FLORESCANO, Enrique (org.). Hacienda, latifundios y plantaciones en América Latina. Simposio de Roma. México: Siglo XXI Editores, 1975

RUBIO DURÁN, Francisco. Viejos y nuevos problemas: una propuesta de superación conceptual para los estudios de ambiente y sociedad. Americania: revista de Estudios Latinoamericanos de la Universidad Pablo de Olavide, IS. L.J, n. 1, p. 102-149, ene. 2011.

SAEGER, James. Supervivencia y abolición: la encomienda paraguaya del siglo dieciocho. In: WHIGHAM, T.; COONEY, J (ed.). Campo y frontera. El Paraguay al fin de la era colonial. Asunción: Servilibro, 2006.

SAVIANI, Demerval. A pedagogia no Brasil: história e teoria. Campinas: Autores Associados, 2008. (Coleção Memória da Educação).

SILVA, Francisco Carlos Teixeira da; LINHARES, Maria. Região e História Agrária. Estudos Históricos, Rio de Janeiro, v. 8, n. 15, p. 17-26, 1995.

SPALDING, Walter. A epopeia farroupilha: Coleção General Benício. Rio de Janeiro: Editora Biblioteca do Exército,1963.

\section{Silvia Lilian Ferro}

Profesora e investigadora del Instituto Latino-americano de Economía, Sociedade e Politica (ILAESP) de la Universidade Federal da Integração Latino-americana (UNILA), Foz do Iguaçu, PR, Brasil. Coordinadora del Grupo de Pesquisa História Ambiental, Rural y Agrária do Cone Sul americano. Doctora por la Universidad Pablo de Olavide (UPO), Sevilla, España. Postdoctorado en la Universidad Nacional de Córdoba e Licenciada en Historia, Universidad Nacional del Litoral, ambas en Argentina.

\section{Dirección:}

Silvia Lilian Ferro

Universidade Federal da Integração Latino-Americana Av. Silvio Américo Sasdelli, 1842

Vila A, 85866-000

Foz do Iguaçu, PR, Brasil. 